\title{
Functional capacity and physical activity level in failed back surgery syndrome patients*
}

\author{
Capacidade funcional e nível de atividade física em pacientes com síndrome dolorosa pós- \\ laminectomia lombar
}

Malu Cristina de Araujo Montoro Lima1, Joice Mara Facco Stefanello², Birgit Keller2, Daniel Benzecry de Almeida ${ }^{3}$, Ricardo Weigert Coelho²

${ }^{*}$ Received from Federal University of Paraná, Curitiba, PR, Brazil.

\section{ABSTRACT}

BACKGROUND AND OBJECTIVES: Failed back surgery syndrome refers to a condition in which a patient has undergone back surgery with a poor outcome. This syndrome leads to losses in daily living activities and hinders the return to physical exercise. The objective of this study was to analyze the relation between chronic low back pain and functional capacity and the physical activity level of these patients.

METHODS: Cross-sectional study comprising 57 patients, mean age $51.07 \pm 12.93$ years, who underwent low back surgery. These patients were divided into two groups, according to the presence of chronic low back pain. All patients filled in a questionnaire that covered demographic data, visual analog scale for pain, Rolland-Morris Questionnaire to evaluate functional incapacity and International Physical Activity Questionnaire to measure physical activity level.

RESULTS: The following predominated: women (77\%), obese (49\%), surgery for spinal disc herniation (80\%), underwent one low back surgery $(52 \%)$. Patients with chronic low back pain refer a greater perception of disability and $81 \%$ of this group showed an average of $3.53 \pm 3.51$ points in Roland-Morris. Chronic low back pain had no influence on the different levels of physical activity demonstrated in patients with chronic low back pain and results of the International Physical Activity Questionnaire showed no significant difference between the groups $(\mathrm{p}=0.54)$.

CONCLUSION: These findings indicate that there were other factors beyond chronic pain interfering with the physical activity

1. University of Contestado, Integrated Colleges of Brazil, Curitiba, PR, Brazil.

2. Federal University of Paraná, Department of Physical Education, Curitiba, PR, Brazil.

3. Institute of Neurology, Gamma Knife Service, Pain Treatment Group, Curitiba, PR, Brazil.

Submitted in August 11, 2014.

Accepted for publication in November 03, 2014

Conflict of interests: none - Sponsoring sources: none.

Correspondence to:

Malu Cristina de Araujo Montoro Lima

Rua Coração de Maria, 92 - Campus Jardim Botânico

80210-132 Curitiba, PR, Brasil.

E-mail: malumontoro@gmail.com

(C) Sociedade Brasileira para o Estudo da Dor level in these groups and further studies to explore lifestyle, physical exercise adherence and other dimensions of pain are still needed. Results contribute to the understanding and management of patients with chronic low back pain.

Keywords: Active life expectation, Failed back surgery syndrome, Low back pain, Sedentary lifestyle.

\section{RESUMO}

JUSTIFICATIVA E OBJETIVOS: A síndrome dolorosa pós-laminectomia lombar é uma condição em que o paciente sofreu uma cirurgia de coluna lombar e os resultados não foram satisfatórios. A dor crônica lombar interfere nas atividades de vida diária e na prática de exercícios físicos regulares. O objetivo deste estudo foi analisar a relação da dor crônica lombar com a incapacidade funcional e o nível de atividade física em pacientes com a síndrome dolorosa pós-laminectomia lombar.

MÉTODOS: Estudo transversal composto por 57 pacientes com idade média de 51,07 $\pm 12,93$ anos que sofreram cirurgia em coluna lombar. Esses pacientes foram divididos em dois grupos seguindo o critério da presença de dor crônica lombar. Os instrumentos utilizados foram questionário para coleta de dados demográficos e clínicos, escala analógica visual, Questionário Roland Morris e Questionário Internacional de Atividade Física. RESULTADOS: Houve prevalência do gênero feminino (77\%), obesos (49\%), cirurgia de hérnia discal lombar (80\%), apenas uma cirurgia (52\%). Pacientes com dor crônica lombar apresentaram uma média de 3,53 $\pm 3,51$ pontos no Roland Morris. A dor crônica lombar não teve influência nos diferentes níveis de atividade física demonstrados no grupo com dor crônica lombar e os resultados do Questionário Internacional de Atividade Física demonstram que não houve diferença significativa entre os grupos $(\mathrm{p}=0,54)$.

CONCLUSÁO: Os achados indicam que existem outros fatores além da dor crônica que interferem no nível de atividade física nesses grupos e que há a necessidade de outros estudos para explorar o estilo de vida, a aderência ao exercício físico e outras dimensóes da dor. Os resultados obtidos contribuíram para o entendimento e manuseio desses pacientes com dor crônica lombar.

Descritores: Dor lombar, Estilo de vida sedentário, Expectativa de vida ativa, Síndrome pós-laminectomia. 


\section{INTRODUCTION}

Chronic low back pain (CLBP) has long been considered a public health problem due either to its high prevalence or to the magnitude of the disability related to it. Therefore, many investigations in different countries have been done, trying to focus on the characteristics of those patients, as well as on many factors related to this disease, trying to establish possible preventive measures ${ }^{1,2}$.

A systematic review of the global prevalence of low back pain that included general population studies published between 1980 and 2009 showed that low back pain has shown to be a major problem throughout the world, with the highest prevalence among women and aged 40-80 years ${ }^{3}$.

According to the World Health Organization (WHO), based on several papers, the economic burden to the society and governmental organizations is quite high. In the United States, the total cost with low back pain exceeds U\$ 100 billion dollars per year ${ }^{4}$. In an epidemiological survey in Hong Kong, $21.8 \%$ of the population ( $\mathrm{n}=1703)$ suffers from CLBP ${ }^{5}$. Studies held in two places in Brazil (Pelotas in the South and Salvador in the Northeast) showed that $4.2 \%(\mathrm{n}=3182)$ and $16.3 \%(\mathrm{n}=2297)$ of the individuals had $\mathrm{CLBP}^{6,7}$.

The initial treatment of lumbar pain is mostly conservative, but surgery may be necessary when the clinical treatment fails to provide adequate pain relief and when there is obvious nerve root and/or spinal cord compression ${ }^{8}$. The most frequent causes of lumbar disc surgery are degenerative disc diseases, osteoarthritis and narrowed spinal canal ${ }^{9}$, being $40 \%$ of the reported cases of CLBP due to discogenic origin ${ }^{10}$.

Failed back surgery syndrome (FBSS) is defined as low back spine or lumbar root pain, usually in the same topographic location, persisting even after surgical intervention or starting after its execution ${ }^{11}$. This condition may develop in 10 to $40 \%$ of patients operated on the lumbar spine ${ }^{12}$.

Patients with CLBP may show a reduction in their functional capacity impacting their ability to perform moderate to vigorous daily activities as cleaning windows, gardening and house cleaning. In addition, their performance of physical exercises can also be affected influencing the choice of exercise, and in many cases causing total interruption of this practice ${ }^{13}$. The actual influence of pain intensity on physical deconditioning and how the avoidance of movement (kinesiophobia) can be related to lack of adherence to a physical exercise program need to be better discussed and understood ${ }^{14,15}$.

We hypothesized that patients with FBSS had a higher rate of perceived disability and a lower level of physical activity.

The aim of this study was to identify whether CLBP really interferes with the functional capacity and the physical activity level of these patients.

\section{METHODS}

Observational, cross-sectional study was conducted between March and October 2011 in Curitiba, Paraná, Brazil. All patients referred by physicians were contacted by phone and an appointment was scheduled. Data collection took place at the Physical Education Department, Federal University of Parana. All patients signed a Free and Informed Consent Term, in compliance with the determination of the National Health Council Resolution 196/96.

The study sample included 57 patients who underwent lumbar surgery at least six months earlier. There were either operated patients with no significant pain or patients with CLBP that were further classified as the FBSS group. Patients were selected by neurosurgeons or orthopedic surgeons. Exclusion criteria were: age under 18; surgery in other regions of the spine other than lumbar; surgery for tumor or spinal cord injury; and surgery performed less than 6 months before evaluation. The first group (G1) consisted of patients with CLBP and the second group (G2) of patients without pain.

All patients filled in a questionnaire about demographic characteristics, lumbar illness, perception of pain, disability, and physical activity level.

Demographic characteristics consisted of age, gender, body mass index, occupational and educational status. Questions about lumbar illness were related to pathological types that preceded the surgery and quantity of surgeries and treatments after surgery. Patients were also asked if they have had CLBP. Pain intensity in those patients with CLBP was evaluated by the verbal analog scale (VAS) ${ }^{16}$. VAS is used worldwide and is easily understandable by the study population. Clear and concise instructions have been given to each patient enabling a quick application with a minimum intervention by the researcher. It is based on a box scale divided in ten boxes (0-10) where zero (0) means "no pain" and ten (10) means "the worst pain ever". Patients with CLBP recorded pain intensity in the VAS in two situations: at awaking time and at 8 p.m.

Disability was measured by The Roland-Morris Disability Questionnaire (RMDQ). This tool is a self-report questionnaire being one of the most widely used tools employed by researchers to measure the degree of disability in people affected by low back spine disorders ${ }^{17,18}$. It consists of 24 questions taken from the impact illness profile ${ }^{19}$. The option "because of my back" was added in each item of the questionnaire. Questionnaire was focused on some physical functions, such as walking, sitting, climbing stairs, dressing up, sleeping, personal care, crouching down and daily activities ${ }^{20}$. Each question had a 'YES' (1) or 'NO' (0) answer. The higher the score, the greater is the functional disability. Validation into Portuguese had been previously published, after applying the questionnaire to 140 patients with CLBP. Internal consistency was very high level (Cronbach's $\alpha$ 0.92).The intraclass correlation coefficient for test-retest reliability was 0.95 (95\% confidence interval, 0.93-0.97). The Brazilian-Portuguese RMDQ version was assessed by calculating the Effect Size with $84 \%$ of confidence interval. The level of responsiveness was 0.10 $(0.04 \text { to } 0.16)^{21}$.

The level of physical activity was measured by the International Physical Activity Questionnaire (IPAQ), version 8, long form. It consists of 27 questions related to physical activity divided into four domains (occupational, transport, household and leisure activities) and the total sitting time reported per week. These ac- 
tivities were observed in a regular week with vigorous, moderate or low intensity, and a minimum of 10 continuous minutes. After all domains in MET (metabolic equivalent) were calculated, physical activity level was classified as low, moderate or high ${ }^{22}$. The Portuguese validation was done in a study with 257 participants, and the Spearman correlation was high and significant $(\text { rho }=0.69 \text { to } 0.71, \mathrm{p}<0.01)^{23}$.

\section{Statistical analysis}

Descriptive statistics detailed the characteristics of groups G1 and G2. Shapiro-Wilk test was applied to verify data normality. In both groups, IPAQ data were not normally distributed while RMDQ was normal only in G1. Nonparametric Mann-Whitney test was used to analyze differences between groups related to RMDQ and to IPAQ. Simple linear regression was used for G1 to check the influence of CLBP on perceived disability. Chi-square test was applied to check the influence of CLBP on the level of physical activity. The level of significance was set to 0.05 for all the tests. Analysis was performed using SPSS V 18.0.

This study was approved by the Health Sciences Sector of the Federal University of Parana under registration number 1048.173.10.11.

\section{RESULTS}

The study sample included 57 patients ( 44 females and 13 males) with mean age of $51.07(\mathrm{SD}=12.93)$. According to body mass index, they were described as: normal weight (30\%), overweight $(21 \%)$ and obese $(49 \%)$. Main causes of surgery were spinal disc herniation $(80.2 \%)$, osteoarthritis $(12.3 \%)$, spinal canal stenosis $(3.5 \%)$, spina bifida $(1.8 \%)$ and bilateral mega apophysis (1.8\%).

In relation to the number of surgeries, 30 patients $(52.6 \%)$ underwent only one low back surgery, while 17 (29.8\%) had two spinal surgeries and $10(17.6 \%)$ three or more surgeries. Physical therapy treatment program has been reported by 21 patients (37\%); while 36 patients (63\%) discontinued this program. Regarding complementary therapies, only 5 patients $(8.8 \%)$ underwent psychological sessions or acupuncture.

Patients were assigned to two groups according to the existence of pain: G1 (Group with CLBP) included 42 patients; and G2 (group without PAIN) with 15 patients. G1 showed a mean score of $5.32(\mathrm{SD}=2.02)$ for pain intensity based on VAS. Demographic characteristics and pathological types that preceded surgery of both groups are shown in table 1 .

Coefficient estimate in linear regression analysis between CLBP and the RMQD score was not significant $(\beta=0.054, R 2=0.003$, $\mathrm{p}=0.736$ ).

Results also showed that $81 \%$ of G1 was considered a poor result based on the classification from the original article, with 14 points or more classified as a poor result, indicating high functional disability 19. There were significant differences between both groups regarding the level of functional capacity $(U=7.50$, $\mathrm{p}=0.000$; table 2). This result demonstrates the impairment of functional capacity in G1.

There was no significant difference between CLBP and the levels of physical activity ( $2=0.5079, \mathrm{p}=0.476)$. IPAQ results showed no significant difference between groups $(\mathrm{p}=0.54)$. G1 presented a mean score of $425(\mathrm{SD}=564.4)$, and G2 presented a MET mean score of $530.6(\mathrm{SD}=705.6)$. There was a prevalence of low level of physical activity in both groups. G2 had one patient with high level of physical activity (Table 3). This patient was considered an outlier, and so his data was removed from the nonparametric test. There was no significant difference between groups regarding their level of physical activity $(\mathrm{U}=262, \mathrm{p}=0.326)$.

Chi-square test showed that CLBP had no influence in the different levels of physical activity demonstrated in G1 (c2=0.5079, $\mathrm{p}=0.476$ ). There was no significant association between CLBP and the levels of physical activity in $\mathrm{G} 1(\mathrm{r}=0.275, \mathrm{p}=0.078)$.

Table 1. Demographic data and main causes of surgery of the participants by group

\begin{tabular}{lcc}
\hline Variables & $\mathrm{G} 1(\mathrm{n}=42)$ & $\mathrm{G} 2(\mathrm{n}=15)$ \\
\hline Age (years) mean (SD) & $53(12.9)$ & $45.6(11.7)$ \\
Gender & 35 & 9 \\
$\quad$ Female & 7 & 6 \\
$\quad$ Male & & \\
Body mass index (category) & 11 & 6 \\
$\quad$ Normal & 22 & 7 \\
$\quad$ Overweight & 9 & 2 \\
$\quad$ Obese & & \\
Pathological types & 32 & 14 \\
$\quad$ Spinal disc herniation & 7 & 0 \\
$\quad$ Osteoarthritis & 2 & 0 \\
$\quad$ Spinal canal stenosis & 0 & 1 \\
$\quad$ Spina bifida & 1 & 0 \\
$\quad$ Bilateral mega-apophasis & & \\
\hline G1: group with pain; G2: group without pain. &
\end{tabular}

Table 2. Roland Morris Disability Questionnaire scores

\begin{tabular}{lcc}
\hline Scores & G1 & G2 \\
\hline Mean(SD) & $16(3.69)$ & $3.53(3.51)$ \\
(min-max) & $(3-23)$ & $(0-11)$ \\
\hline G1:
\end{tabular}

Table 3. Level of physical activity in groups

\begin{tabular}{lcc}
\hline IPAQ & G1 & G2 \\
\hline Low & $30(71.4 \%)$ & $12(80 \%)$ \\
Moderate & $12(28.6 \%)$ & $2(13.3 \%)$ \\
High & 0 & $1(6.7 \%)^{\star}$
\end{tabular}

IPAQ: International Physical Activity Questionnaire; *Outlier.

\section{DISCUSSION}

Results of this study support the hypothesis that the CLBP presented by patients with FBSS show high prevalence of functional disability. But the authors found a prevalence of low level of physical activity in both groups with no significant association 
between CLBP and different levels of physical activity in the group with CLBP.

Herniated lumbar intervertebral disk was the most common condition reported by patients with CLBP ${ }^{24}$. Surgery is indicated when a conservative treatment fails. The present study showed that $80.2 \%$ of patients had herniated lumbar intervertebral disk.

This research included 42 patients presenting CLBP, who were taken to the health service and diagnosed with FBSS. Ongoing low back pain is a major complication after lumbar spinal surgeries. The etiology of this painful disorder is discussed at length by many health researchers, since it includes surgical and non-surgical factors, ranging from psychosocial factors, surgical factors, and reviews of surgeries due to postsurgical complications?. CLBP may impair functional capacity during daily activities. The knowledge of these effects is important, since strategies of intervention taken by health professionals should be based on such data. Health condition or treatment results are usually evaluated by self-report questionnaires. RMQD is one of the most common scales used by researchers to measure functional capacity in patients with $\mathrm{CLBP}^{17,25}$. In the original article, the result of 14 points or more was considered as bad result inferring high functional incapacity ${ }^{22}$. This research showed significant difference between groups with regard to RMDQ scores. G1 patients showed a mean score of 16 points $(\mathrm{SD}=3.69$, table 2$)$ and $81 \%$ of these patients were classified as highly functionally disabled. The evaluation of results of low back surgery is highly important because it helps the improvement of medical surgery techniques and materials, and the understanding of psychological and physical characteristics of the patient. Signals and symptoms like pain, physical condition, kind of surgery and disability were major determinants to evaluate post-surgical results in a prospective research with a two-year follow up carried out with 185 patients who underwent lumbar spine surgery ${ }^{26}$.

The present study showed $47.7 \%$ of these patients underwent two or more low back surgery. Sometimes, another surgery is indicated to recover from pain and functional incapacity. A case series of 82 patients with mean follow-up period of 15 months after instrumented fusion for treatment of failed back surgery, has shown that $65 \%$ of patients reported unsatisfactory outcome. Mean VAS score for low back pain was $4.57 \pm 2.9$ and $30.6 \pm 20.3^{27}$.

RMDQ is more responsive with patients with high levels of activity limitation. A study with 803 patients that evaluated data from four randomized controlled trials registered in Australia New Zealand Clinical Trials Registry showed that functional incapacity measured with RMDQ was $11.9 \pm 6.5$ and mean pain scores at baseline were 6.2 \pm 2.0 .28 .

Patients who underwent low back surgery expect a normal return to their daily life activities. A prospective study with a five-year follow up has shown improvement in the functional capacity of the groups with a mean score according to the Oswestry Total Disability Index of $40.7 \%$ before surgery (severe disability) and $25.3 \%$ (moderate disability) after surger ${ }^{29}$. Another study has found that the intensity of pain in patients after six months of lumbar surgery showed a negative relation with the level of physical activity reported ${ }^{30}$. Although our study did not present a pre-operative evaluation, we have found a high rate of functional incapacity as compared to patients who underwent lumbar surgery, regardless of the time of surgery or the time of signs and symptoms.

The relationship between disability, quality of life and fear-avoidance beliefs in patients with CLBP was evaluated by researchers in many countries. A cross-sectional study comprising 105 patients showed that when the severity of pain increased, physical function decreased and disability $(15.43 \pm 6.05$, RMDQ) increased as fear-avoidance increased ${ }^{31}$.

Our study showed a prevalence of low level of physical activity in both groups. These findings confirm the presence of other factors that lead to low level of physical activity in patients who underwent low back surgery.

Physical activity is defined as any body movement produced by the muscles and resulting in energy expenditure ${ }^{32}$. The daily routine of patients with FBSS can be changed with the presence of CLBP. In this case, the healthcare team that assists these patients should keep in mind the level of physical activity for the planning of their actions. Many tools have been developed and applied in order to measure the level of physical activity either in epidemiological studies or in the analysis of treatment results. IPAQ was developed by the World Health Organization with the objective of establishing the prevalence of physical activity worldwide ${ }^{22}$. This tool divides physical activities into four domains (occupational, transport, household and leisure activities). They combine walking, pedalling and moderate or vigorous physical activity to demonstrate the physical activity level presented by individuals. There was no significant difference between both groups regarding the level of physical activity in our study, since there was a low level prevalence. These results have shown that patients submitted to surgery tend to adopt protective measures to avoid lumbar spine impairment. This procedure can interfere with their choice of daily routine activities. Another study used an accelerometer to check the level of physical activity in individuals with CLBP and reported a low level of physical activity with a reduction of $29 \%$ of their steps within a period of 24 hours as compared to the level in the control group ${ }^{33}$.

Epidemiological researches on physical activity and chronic low back pain have shown that the relationship between these variables can be a relationship in a ' $U$ ' shape indicating that quantity of physical activity is dangerous to lumbar spine health. Heneweer, Vanhees and Picavet ${ }^{34}$ evaluated 758 subjects (26.9\% of the sample) with CLBP and scored their physical activity through a tool similar to IPAQ, concluding that extremes of the pattern of AF were associated to a high prevalence of CLBP.

Patients with CLBP often feel unable to perform their daily activities, developing a model of fear and avoidance of situations that may worsen their pain, characterizing a behavior of kinesiophobia ${ }^{13}$. Psychological factors should also be taken into account such as fear of movement, occurrence of new lesions or compromising the performed surgical procedure. These factors have been related to patient's perception of pain ${ }^{15}$. 


\section{CONCLUSION}

This study has limitations that should be considered after the interpretation of results.

A first limitation is related to the use of a questionnaire (IPAQ) to check the level of physical activity with a tendency to overestimate the level of physical activity of the patient.

The second limitation was lack of preoperative evaluation of patients with FBSS. Further researches of patients' behavior in relation to CLBP and to their lifestyle as well as multidimensional pain assessment are needed.

Results of this study demonstrated that CLBP prevalent in patients with FBSS can be associated to other factors that determine their functional incapacity and low level of physical activity.

\section{REFERENCES}

1. Björck-van Dijken C, Fjellman-Wiklund A, Hildingsson C. Low back pain, lifestyle factors and physical activity: a population-based study. J Rehabil Med. 2008;40(10):864-9.

2. Seery MD, Leo RJ, Holman EA, Silver RC. Lifetime exposure to adversity predicts functional impairment and healthcare utilization among individuals with chronic back pain. Pain.2010;150(3):507-15.

3. Hoy D, Bain C, Willians G, March L, Brooks P, Blyth F, et al. A systematic review of the global prevalence of low back pain.Arthritis Rheum.2012;64(6):2028-37.

4. Miller B, Gatchel RJ, Lou L, Stowell A, Robinson R, Polatin PB. Interdisciplinary treatment of failed back surgery syndrome (FBSS): a comparison of FBSS and non-FBSS patients. Pain Pract. 2005;5(3):190-202.

5. Wong WS, Fielding R. Prevalence and characteristics of chronic pain in the general population of Hong Kong. J Pain. 2011;12(2):236-45.

6. Sá KN, Baptista AF, Matos MA, Lessa I.Chronic pain and gender in Salvador population, Brazil. Pain.2008;139(3):498-506.

7. Silva MC, Fassa AG, Valle NC. Chronic low back pain in a Southern Brazilian adult population: prevalence and associated factors. Cad Saude Publica. 2004;20(2):377-85. Portuguese.

8. Mannion AF, Elfering A. Predictors of surgical outcome and their assessment. Eur Spine J. 2006;15(Suppl 1):S93-108

9. Chan CW, Peng P. Failed back surgery syndrome. Pain Med. 2011;12(4):577-606.

10. Buric J, Pulidori M.Long-term reduction in pain and disability after surgery with the interspinous device for intervertebral assisted motion (DIAM) spinal stabilization system in patients with low back pain: 4-year follow-up from a longitudinal prospective case series. Eur Spine J.2011;20(8):1304-11.

11. Merskey H, Bogduk N. Classification of chronic pain: descriptions of chronic pain syndromes and definitions of pain terms, Seattle: IASP Press; 1994.

12. Skaf G, Bouclaous C, Alaraj A, Chamoun R. Clinical outcome of surgical treatment of failed back surgery syndrome. Surg Neurol. 2005;64(6):483-9.

13. Koho P, Orenius T, Kautiainen H, Haanpää M, Pohjolainen T, Hurri H.Association of fear of movement and leisure-time physical activity among patients with chronic pain. J Rehabil Med.2011;43(9):794-9.

14. Smeets RJ, van Geel KD, Verbunt JA.Is the fear avoidance model associated with the reduced level of aerobic fitness in patients with chronic low back pain? Arch Phys
Med. 2009;90(1):109-17.

15. Van Hooff ML, Van der Merwe JD, O’ Dowd J, Pavlov PW, Spruit M, De Kleuver M et al. Daily functioning and self-management in patients with chronic low back pain after an intensive cognitive behavioral programme for pain management. Eur Spine J.2010;19(9):1517-26.

16. Haefeli M, Elfering A. Pain assessment. Eur Spine J. 2006;15(Suppl 1):S17-24.

17. Hush JM, Refshauge KM, Sullivan G, De Souza L, McAuley JH.Do numerical rating scales and the Roland-Morris Disability Questionnaire capture changes that are meaningful to patients with persistent back pain? Clin Rehabil.2010;24(7):648-57.

18. Ostelo RW, De Vet HC, Knol DL, van den Brandt PA. 24-item Roland-Morris Disability Questionnaire was preferred out of six functional status questionnaires for post-lumbar disc surgery. J Clin Epidemiol.2004;57(3):268-76.

19. Bergner M, Bobbitt RA, Carter WB, Gilson BS. The sickness impact profile: development and final revision of a health status measure. Med Care.1981;9(8):787-805.

20. Roland M, Morris R. A study of the natural history of low back pain. Part I: development of a reliable and sensitive measure of disability in low back pain. Spine. 1983;8(2):141-4.

21. Costa LO, Maher CG, Latimer J, Ferreira PH, Pozzi GC, Ribeiro RN. Psychometric characteristics of the Brazilian-Portuguese versions of the Functional Rating Index and the Roland Morris Disability Questionnaire. Spine.2007;32(17):1902-7.

22. Craig CL, Marshall AL, Sjöström M, Bauman AE, Booth ML, Ainsworth BE, et al International physical activity questionnaire: 12 -country reliability and validity. Med Sci Sports Exerc.2003;35(8):1381-95.

23. Matsudo S, Araújo T, Matsudo V, Andrade D, Andrade E, Oliveira LC, et al. Questionário Internacional de Atividade Física (IPAQ): estudo de validade e reprodutibilidade no Brasil. Rev Bras Ativ Fís Saúde.2001;6(2):5-18.

24. Tropiano P, Huang RC, Girardi FP, Camisa FP Jr, Marnay T.Lumbar total disc replacement. J Bone Joint Surg Am.2005; 87(3):490-6.

25. Schiphorst Preuper HR, Reneman MF, Boonstra AM, Dijkstra PU, Versteegen GJ, Geertzen JH. The relationship between psychosocial distress and disability assessed by the Symptom Checklist-90-Revised and Roland Morris Disability Questionnaire in patients with chronic low back pain. Spine J.2007;7(5):525-30.

26. Waddell G, Reilly S, Torsney B, Allan DB, Morris EW, Di Paola MP, et al. Assessment of the outcome of low back surgery. J Bone Joint Surg Br. 1988;70(5):723-7.

27. Arts MP, Kols NI, Onderwater SM, Peul, WC. Clinical outcome od instrumented fusion for the treatment of failed back surgery syndrome: a case series of 100 patients. Acta Neurochir.2012;154(7):1213-7.

28. Hall AM, Maher CG, Latimer J, Ferreira ML, Costa LO. The patient-specific functional scale is more responsive than Roland Morris disability questionnaire when activity limitation is low. Eur Spine J.2011;20(1):79-86.

29. Santavirta N, Björvell H, Konttinen YT, Solovieva S, Poussa M, Santavirta S. Sense of coherence and outcome of low-back surgery: 5-year follow-up of 80 patients. Eur Spine J.1996;5(4):229-35.

30. Hasenbring MI, Plaas H, Fischbein B, Willburger R. The relationship between activity and pain in patients 6 months after lumbar disc surgery: do pain-related coping modes act as moderator variables? Eur J Pain. 2006;10(8):701-9.

31. Guclu DG, Guclu O, Ozaner A, Senormanci O, Konkan R. The relationship between disability, quality of life and fear-avoidance beliefs in patients with chronic low back pain. Turk Neurosurg.2012;22(6):724-31.

32. Caspersen CJ, Powell KE, Christenson GM.Physical activity, exercise, and physical fitness: definitions and distinctions for health-related research. Public Health Rep.1985;100(2):126-3.

33. Ryan CG, Grant PM, Dall PM, Gray H, Newton M, Granat MH. Individuals with chronic low back pain have a lower level, and an altered pattern, of physical activity compared with matched controls: an observational study. Aust J Physiother. 2009;55(1):53-8.

34. Heneweer H, Vanhees L, Picavet HS. Physical activity and low back pain: A U-shaped relation? Pain. 2009;143(1-2):21-5. 